\title{
IMPROVED METHODS FOR IMMUNO-ELECTRON MICROSCOPY OF CULTURED CELLS: USE OF A NOVEL SUBSTRATE AND APPLICATION OF MICROWAVE IRRADIATION
}

\author{
Shinji MATSUTANI ANd Noboru YAMAMOTO \\ Department of Functional Morphology, Kitasato University School of Nursing, \\ Sagamihara, Kanagawa 228
}

Received for publication February 9, 1990 and in revised form February 28, 1990

\begin{abstract}
For immuno-electron-microscopic observations of cultured cells, we used a novel substrate, a commonly used domestic wrapping film, for plating cells, and irradiated microwave (MW) during fixation or during post-embedding immunoreaction. Isolated hepatocytes cultured on wrapping film could be observed under a phase-contrast microscope, appeared healthy, and were sectioned in various orientations for electron microscopy. Post-embedding immunogold staining was carried out on these sections, and the density of gold particles was used to estimate the effects of MW irradiation. Although MW irradiation (60 sec) during fixation brought about a comparable density to that of conventional fixation (15min immersion), the preservation of fine structures was poorer in irradiated specimens. The time required for the reaction with primary antibody was reduced with MW irradiation. Sixty-second irradiation was shown to give an equivalent result to overnight reaction without irradiation.
\end{abstract}

A variety of cellular functions are influenced by cell-cell and/or cell-matrix interactions. Morphological observations of cultured cells are useful for a better understanding of these interactions, the spatial aspects of which can be seen under some controlled conditions, and can be correlated with localizations of particular substances with the aid of immunocytochemistry. In particular, immunoelectron microscopy, which offers definite information, seems to be essential for these observations.

Although several methods have been developed for the electron-microscopic observation of cultured cells attached to a substrate $(2,4)$, each of them have some shortcomings with respect to the preservation of cell orientation or the ease of handling. In order to resolve these problems, we tried a novel substrate, a domestic wrapping film, which might fulfill the demands required for plating cells.

Microwave (MW) irradiation has been coming into wide use for the fixation of tissues $(1,8-12,15)$. Hence the effects of $\mathrm{MW}$ irradiation on fixation and immunocytochemical stainings for immuno-electron microscopy were examined using cells cultured on the new substrate.

This paper focuses on the results of these trials, and shows better procedures for the preparation of immuno-electron microscopic specimens. 


\section{MATERIALS AND METHODS}

\section{Culture Substrate}

For a culture subtrate, we used a domestic wrapping film, Saran Wrap (Asahi Chemical Industry Co., Tokyo), made of polychlorovinylidene. A piece of Saran Wrap was clamped between two flat acrylic rings (1-3 mm in thickness, $33 \mathrm{~mm}$ in inner diameter) which were fixed to each other with laboratory film, Parafilm (American Can Co., Greenwitch, CT) and vinyl tape. This "Saran Wrap dish" was then autoclaved and coated with $100 \mu \mathrm{g} / \mathrm{ml}$ of collagen (obtained from Koken Co., Tokyo) before use.

\section{Cell Preparation}

Hepatocytes were prepared from normal rat livers as described previously (14). In brief, they were isolated by collagenase perfusion, centrifuged through a Percoll gradient to remove dead cells, washed with Hanks' balanced salt solution, and suspended in a culture medium consisting of $90 \%$ Dulbecco's modified Eagle minimum essential medium, $10 \%$ fetal calf serum, $5 \mu \mathrm{g} / \mathrm{ml}$ insulin, $100 \mathrm{units} / \mathrm{ml}$ penicillin and $100 \mu \mathrm{g} / \mathrm{ml}$ streptomycin. They were then plated on the "Saran Wrap dish" at a density of $3 \times$ $10^{4}$ cells $/ \mathrm{cm}^{2}$, and cultured for 2 or 3 days in a moist atmosphere of $5 \% \mathrm{CO}_{2}$ in air at $37^{\circ} \mathrm{C}$.

Conventional electron microscopy using Saran Wrap

The Saran Wrap was removed from the acrylic rings, and the cultured hepatocytes together with the Saran Wrap were fixed with phosphate-buffered glutaraldehyde solution (1\%) for 15 min, post-fixed with $1 \% \mathrm{OsO}_{4}$, dehydrated in a graded series of ethanol, infiltrated with propylene oxide or butylglycidyl ether, cut into small pieces, and embedded in an epoxy resin, Quetol-812 (Nissin EM, Tokyo).

Sixty-nm sections were cut with a diamond knife, stained with uranyl acetate and lead tartrate, and examined under a Hitachi H-7000 electron microscope.

Evaluation of the effects of $M W$ fixation on immunoreaction

Rabbit antibody against rat plasma fibronectin was affinity-purified after the method of Engvall and Ruoslahti (5) with minor modifications and used in this assay.

The Saran Wrap was removed from the acrylic rings, and the cultured hepatocytes together with the Saran Wrap were fixed with $2 \mathrm{ml}$ of $0.1 \mathrm{M}$ phosphate buffer ( $\mathrm{pH} 7.2$ ) containing $3 \%$ paraformaldehyde and $0.25 \%$ glutaraldehyde in a plastic dish (35 mm in diameter) under MW irradiation which was delivered by a domestic MW oven (Model ER-250, Toshiba, Tokyo) operated at 2,450 MHz with the heat setting at $500 \mathrm{~W}$. Five-second bursts of irradiation were repeated at intervals of $5 \mathrm{sec}$ until the total irradiation time reached $60 \mathrm{sec}$. Consequently, the whole fixation time amounted to approximately $2 \mathrm{~min}$. The MW irradiation with this time sequence raised the temperature of the fixative from $4^{\circ} \mathrm{C}$ to approximately $30^{\circ} \mathrm{C}$. For controls, some samples were fixed for $15 \mathrm{~min}$ at room temperature without $\mathrm{MW}$ irradiation.

After the fixation, samples were dehydrated in a graded series of ethanol, cut into small pieces, immersed in a methacrylic resin, LR-White (London Resin Co., Hants, England), and the resin was polymerized at $4^{\circ} \mathrm{C}$ for 2 days. They were then sectioned (60 $\mathrm{nm}$ in thickness), collected on formval-coated nickel mesh, preincubated with $1 \%$ bovine serum albumin (BSA) in $10 \mathrm{mM}$ phosphate-buffered saline (PBS), and reacted overnight at $4^{\circ} \mathrm{C}$ with anti-fibronectin antibody at a concentration of $10 \mu \mathrm{g} / \mathrm{ml}$. Subsequently sections were washed in PBS containing $1 \%$ BSA, followed by incuba- 
tion with $50 \mathrm{mM}$ Tris- $\mathrm{HCl}$ buffer containing $0.1 \%$ Tween 20 , and reacted with colloidal gold-labeled goat anti-rabbit IgG (E. Y Labs, San Mateo, CA) for $30 \mathrm{~min}$ at room temperature.

Finally, they were stained with uranyl acetate and lead tartrate, examined and randomly photographed at a magnification of $\times 10,000$. Since fibronectin is known to localize in the extracellular matrix between the cell and substrate $(4-7,13)$, the number of gold particles on the matrix was counted on photographs printed at a magnification of $\times 2.5$ to evaluate the effects of MW irradiation on the fixation of the antigen. The density of particles was expressed as the number per length of extracellular matrix between the cell and substrate. The number of particles on the cell nucleus, where fibronectin is unlikely to localize, was also counted to estimate nonspecific reactions. In this case, the density was expressed as the number of particles per area.

Evaluation of the effects of $M W$ irradiation on the post-embedding immunoreaction

Hepatocytes embedded in LR-White were sectioned and preincubated with $1 \%$ BSA solution. They were subsequently reacted with rabbit anti-actin antibody (Transformation Research Inc.) under MW irradiation. Samples were put on a drop of antibody solution (10 $\mu \mathrm{g} / \mathrm{ml}$ in concentration, 40-50 $\mu \mathrm{l} / \mathrm{drop})$. MW was delivered in the same manner as described above, except that total irradiation time was either 15,30 or $60 \mathrm{sec}$. After 60 -sec irradiation, the temperature of the antibody solution was raised from $4^{\circ} \mathrm{C}$ to approximately $25^{\circ} \mathrm{C}$. Sections were left on the antibody solution for $15 \mathrm{~min}$ after the MW irradiation, washed and reacted with colloidal gold-labeled secondary antibody as described. For control experiments, some samples were reacted with primary antibody without $\mathrm{MW}$ irradiation; one group of sections was reacted at room temperature for $17 \mathrm{~min}$ (which equaled the total reaction time for sections subjected to the 60 -sec MW irradiation), another group was reacted overnight at $4^{\circ} \mathrm{C}$. In some reactions, nonimmune rabbit IgG was substituted for anti-actin antibody for negative controls. The number of particles was counted in photographs printed at a final magnification of $\times 50,000$. The density of particles was expressed as the number per area.

\section{RESULTS}

Cells cultured on collagen-coated Saran Wrap appeared healthy. Compared to cells cultured on collagen-coated plastic dishes, no difference was found in their attachments and extensions under phase-contrast microscopic observations (Fig. 1). The Saran Wrap was easy to handle during the preparation of electron microscopic specimens, and could be sectioned in various orientations to reveal cell polarities and arrangements (Fig. 2). Saran Wrap was insoluble in ethanol, acetone, propylene oxide and butylglycidyl ether. Both epoxy (Quetol-812) and methacrylic resin (LRWhite) were available for embedding Saran Wrap.

Effects of $M W$ fixation on immunoreaction

As shown in Table 1, no significant difference was detected between the two procedures, fixation under $60-\mathrm{sec} \mathrm{MW}$ irradiation and by a 15 -min immersion, with respect to the density of gold particles. The result suggested that the 2-min fixation with MW irradiation achieved results comparable to those of conventional fixation. However, the preservation of fine structures was poorer in samples fixed under MW ir- 


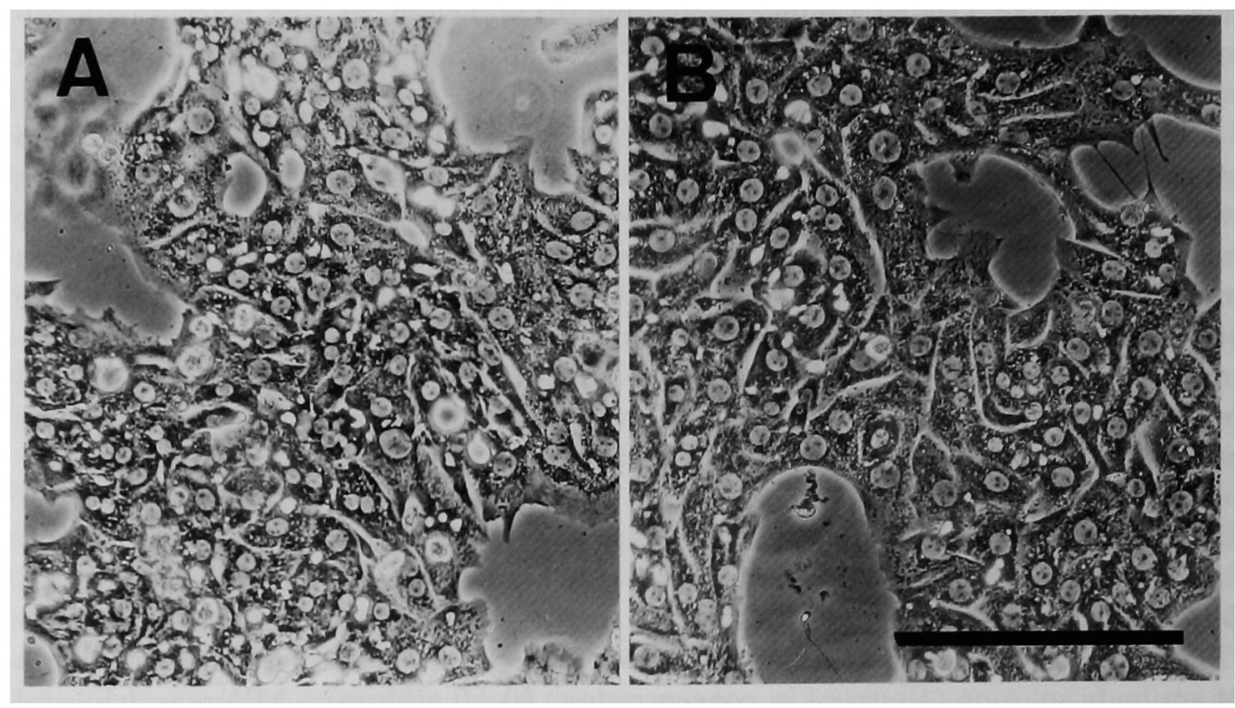

Fig. 1. Hepatocytes grown on Saran Wrap (A) and on a plastic dish (B). Almost no differences are found in cell attachments and extensions between the two groups. Bar: $500 \mu \mathrm{m}$

radiation (Fig. 3).

Effects of $M W$ irradiation on the post-embedding immunoreaction

The density of gold particles increased as the duration of the total irradiation was extended, and in samples irradiated for $60 \mathrm{sec}$, it reached almost the same value as controls reacted overnight without MW irradiation (Fig. 4). The immunoreactions under MW irradiation seemed as specific and intense as those of the controls, judging from photographs (Fig. 5). Dense distribution of gold particles was seen just beneath the plasma membrane, a well-known site for localization of actin molecules. The substitution of nonimmune rabbit IgG for anti-actin antibody produced a negligible density of labeling even in samples irradiated for $60 \mathrm{sec}$ (data not shown). These results suggest that $\mathrm{MW}$ irradiation greatly reduces the time required for immunoreaction.

TABLE 1. Effect of $M W$ fixation on immunoreaction

\begin{tabular}{lccc}
\hline & Time (min) & $\begin{array}{c}\text { Specific } \\
\text { Reaction* }\end{array}$ & $\begin{array}{c}\text { Non-specific } \\
\text { Reaction }\end{array}$ \\
\hline MW Fixation & 2 & 3.7 & 0.5 \\
Immersion & 15 & 3.3 & 0.6 \\
\hline
\end{tabular}

* The density of particles (particle/ $\mu \mathrm{m}$ )

** The density of particles (particle/ $\mu \mathrm{m}^{2}$ ) 


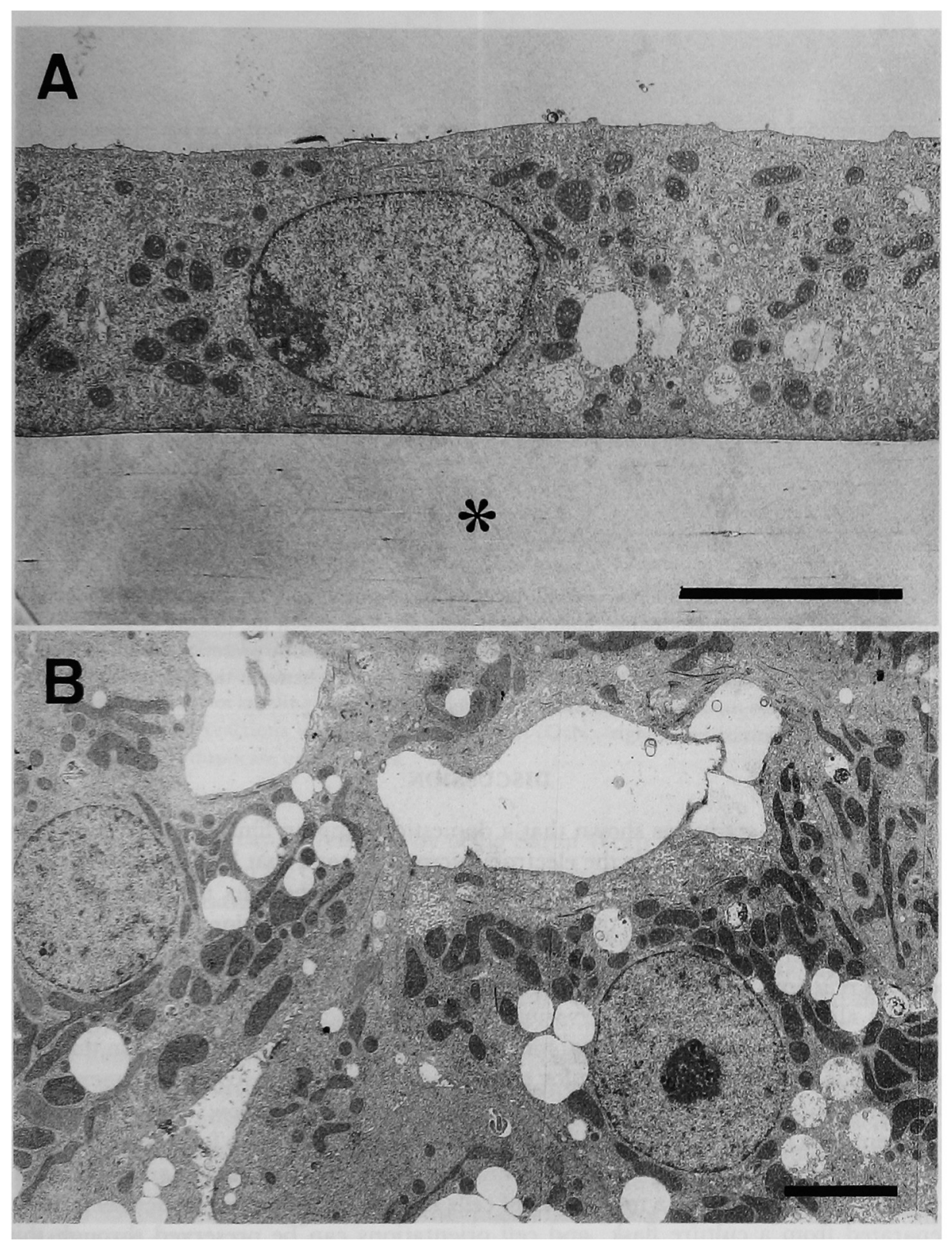

FIG. 2. Electron micrographs of hepatocytes cultured on Saran Wrap and embedded in epoxy resin (Quetol-812). Sections can be cut in vertical (A) or tangential (B) orientations against the plane of the substrate. In A, Saran Wrap is seen beneath the cell (asterisk). Bar: $5 \mu \mathrm{m}$ 


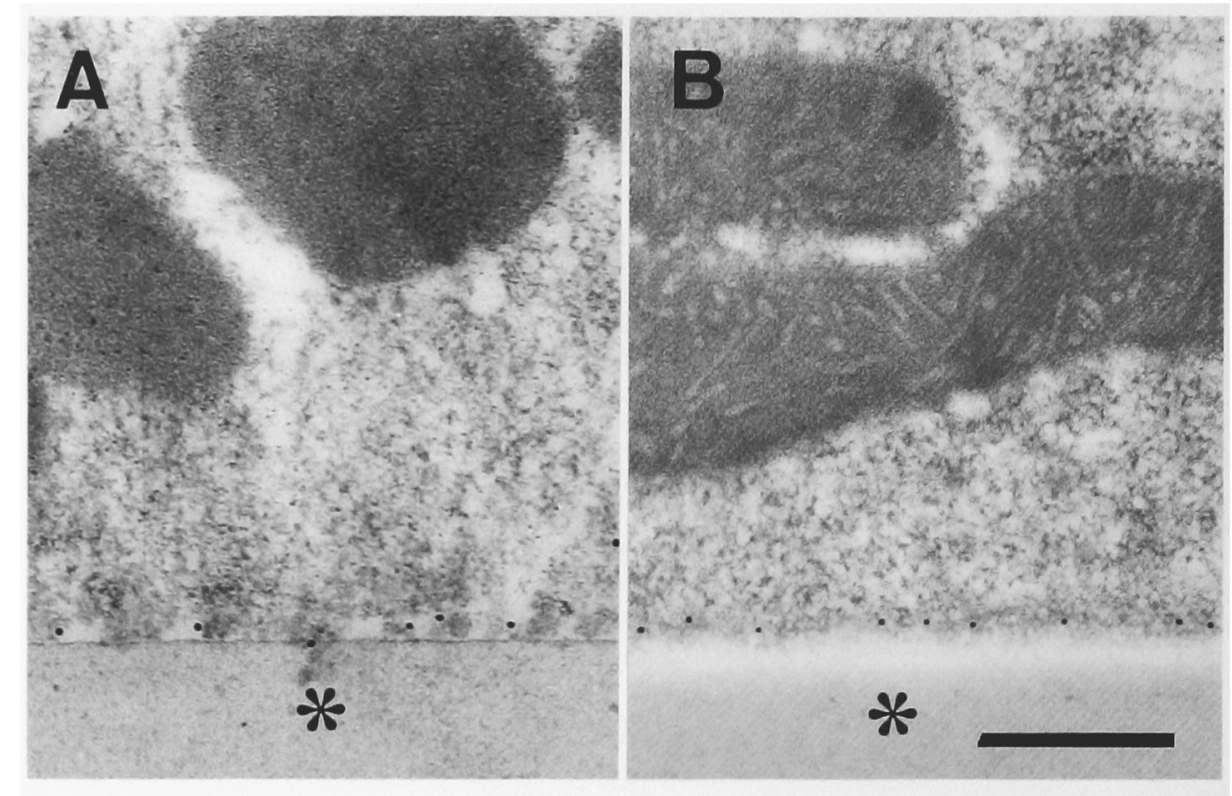

Figs. 3A, B. Immuno-electron microscopic labeling for fibronectin. A. A sample fixed under MW irradiation. B. A sample fixed without MW irradiation. Although the density of gold particles are almost identical in both specimens, mitochondrial cristae are poorly preserved in the sample fixed under MW irradiation. Saran Wrap (asterisks) can be seen beneath the cells. Bar: $0.5 \mu \mathrm{m}$

\section{DISCUSSION}

The present study has shown that a domestic wrapping film, Saran Wrap, is an excellent culture substrate for the electron microscopy, and that MW irradiation during the post-embedding immunostainings significantly shortens the reaction time. The study has also revealed that fixation under $\mathrm{MW}$ irradiation results in poorer preservation of fine structures, although no significant difference in the intensities of positive reactions is detected, compared to conventional fixation.

As already noted, the observations of cell-cell and cell-matrix relationships in cultured adherent cells are essential for studies in the field of cell biology. In this context, although several procedures for preparing electron-microscopic specimens have been introduced, they have some disadvantages as described below. Detachments of adherent cells from the substrate (3), followed by centrifugation to form a pellet, result in a loss of cell morphology and/or orientation. Alternatively, using an organic solvent, butylglycidyl ether, a monolayer of cells together with a thin plastic sheet can be separated from a culture flask, and cell orientations can be preserved through this "floating sheet" method (2). However, the sheet can not always be handled with ease during the preparations. A cross-linked gelatin film (4) takes a long time to prepare, compared to using ready-made materials. Although a polycarbonate filter membrane is often used as a substrate, because of its darkness the living state of cells cannot be observed under a light microscope during cultu 


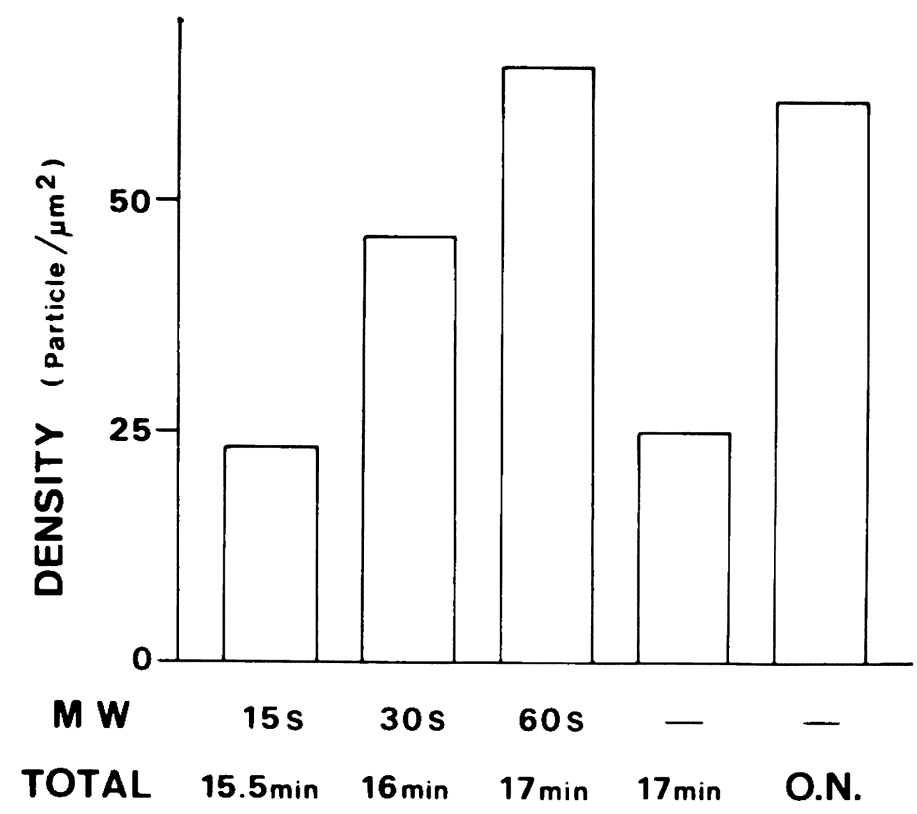

Fig. 4. Effects of MW irradiation during post-embedding immunoreaction on the density of immuno-gold labeling for actin. The length of $\mathrm{MW}$ irradiation and the total time required for the reaction are shown below each column. A positive relationship between the length of $M W$ irradiation and the density of labeling is noticed, and 60 -sec irradiations bring about results comparable to those of overnight reactions without MW irradiation (O.N., right-hand column). Each value is representative of duplicate experiments.

These problems can be resolved by using Saran Wrap as a culture substrate. As described, the film can be easily manipulated and sectioned without losing cell morphology and orientation, and it is resistant to various organic solvents commonly used during the preparation of electron-microscopic specimens. In addition, cells plated on Saran Wrap, due to its transparency, can be observed and photographed under a light microscope during culture. The use of this common, economic material thus seems advantageous for electron microscopy of cultured cells.

In histochemical tissue processing, MW irradiation has been applied mainly to fixation, and is reported to enhance fixation quality in general $(1,8-12,15)$. In the present study, we failed to detect such enhancement in fixation quality. This discrepancy may result from differences in the procedures employed. Yasuda et al. (15) reported that good results were obtained with fixative the temperature of which was raised to $45-50^{\circ} \mathrm{C}$, and suggested that the quality of fixation depends on rapid heating by MW, rather than the duration of irradiation. Indeed, according to other reports, satisfying results were obtained with relatively high fixation temperatures (above $50^{\circ} \mathrm{C}$ ), but the duration of irradiation varied (10-12). In our experiment, the final temperature was lower (about $30^{\circ} \mathrm{C}$ ) than those in these reports, and this difference might bring about poorer fixation. To our knowledge, few studies deal with the effects of MW on the fixation of cultured cells (12). Our fixation protocol for cultured 


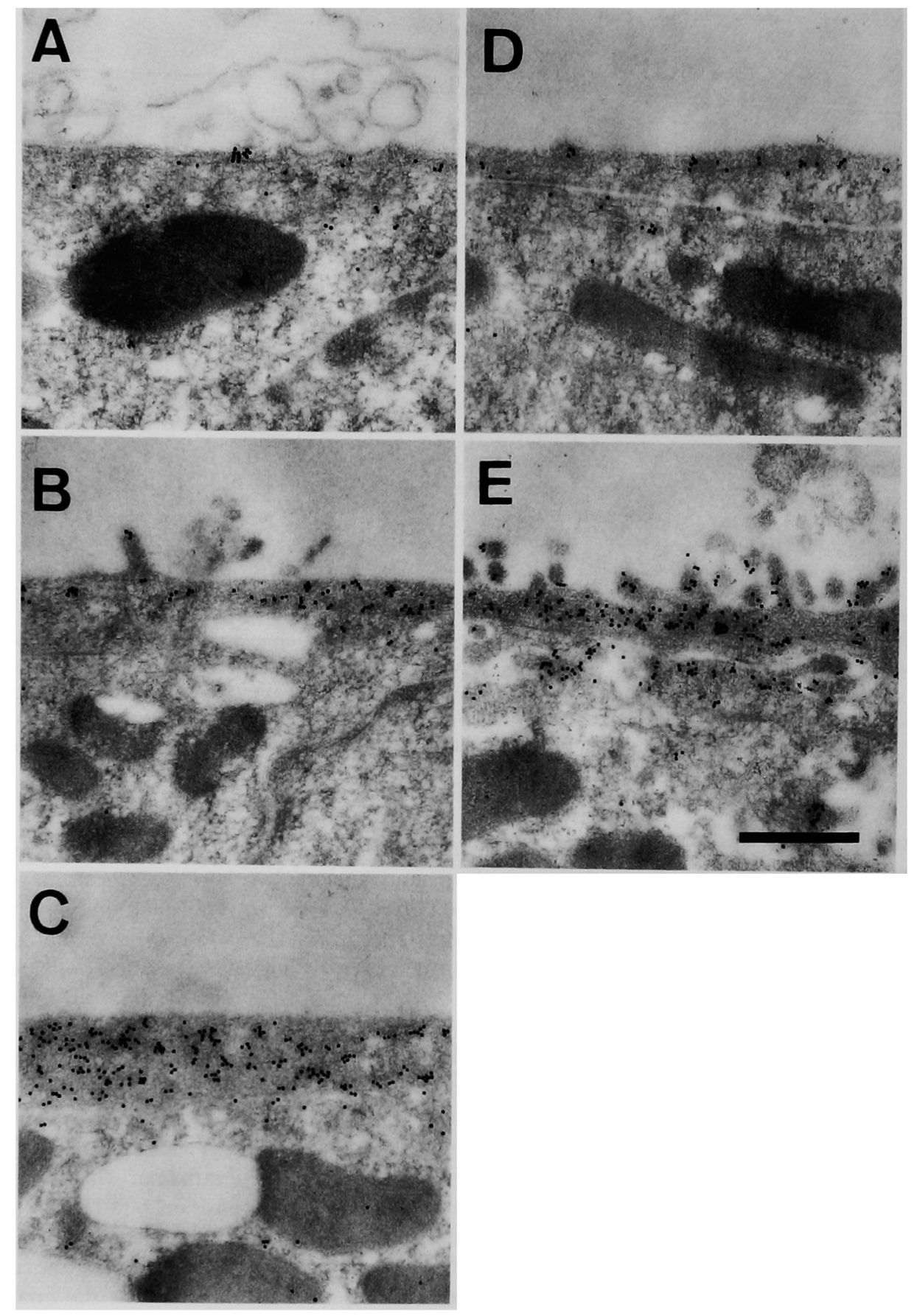

Figs. 5A-E. Immuno-electron microscopic labeling for actin. A-C. Specimens irradiated with MW for 15 (A), 30 (B) and $60 \mathrm{sec}(\mathrm{C})$ during immunoreactions with primary antibody. D and E. Specimens reacted for $17 \mathrm{~min}(\mathrm{D})$ and overnight (E) without MW irradiation. The density of gold particles in $\mathrm{C}$ is comparable to that seen in $\mathrm{E}$. Bar: $0.5 \mu \mathrm{m}$ 
cells should be improved.

The present results show that MW irradiation shortens the time required for post-embedding immunocytochemical reactions. The intensity of labeling increased as the duration of irradiation extended. Although the physical conditions of antigens under MW irradiation are largely unknown, MW may accelerate the vibration of the water molecule and thereby increase the probability of collisions between antigens and antibodies.

Our protocol of MW irradiation produced a moderate rise in the temperature of the antibody solution. In our experiment, the specimens were put on a drop of reaction solution (40-50 $\mu \mathrm{l} / \mathrm{drop})$, and irradiated for as long as $60 \mathrm{sec}$. Subsequently, the final temperature of the antibody solution was measured at $25^{\circ} \mathrm{C}$. These conditions may allow the application of MW irradiation for immunocytochemical detection of heat-labile substances.

The use of cultured cells has various advantages for the morphological approach to understanding cell-cell and cell-matrix interactions. While methodologies for morphological analyses are under development, further improvements seem to be necessary.

\section{REFERENCES}

1. Armati, P. J., Pollard, J. D., Van Reyk, D. and Van der Lubbe, L.: Neuroimmunological electron microscopy with microwave-accelerated fixation. J. Immunol. Meth. 110; 267-269, 1988.

2. Arnold, J. R. and Boor, P. J.: Improved transmission electron microscopy (TEM) of cultured cells through a "floating sheet" method. J. Ultrastruct. Mol. Struct. Res. 94; 30-36, 1986.

3. Casey, M. L., MacDonald, P. C., Mitchell, M. D. and Snyder, J. M.: Maintenance and characterization of human myometrial smooth muscle cells in monolayer culture. In Vitro 20; 396-403, 1984

4. Chen, W.-T. and Singer, S. J.: Immunoelectron microscopic studies of the sites of cellsubstratum and cell-cell contacts in cultured fibroblasts. J. Cell Biol. 95; 205-222, 1982.

5. Engvall, E. and Ruoslahti, E.: Binding of a soluble form of fibroblast surface protein, fibronectin, to collagen. Int. J. Cancer 20;1-5, 1977.

6. Furcht, L. T., Mosher, D. F . and Wendelschafer-Crabb.: Immunocytochemical localization of fibronectin (LETS protein) on the surface of L6 myoblasts: light and electron microscopic studies. Cell $13 ; 263-271,1978$.

7. Hedman, K., Vaheri, A. and Wartiovaara, J.; External fibronectin of cultured human fibroblasts is predominantly a matrix protein. J. Cell Biol. 76; 748-760, 1978.

8. Leong, A. S.-Y., Daymon, M. E. and Milios, J.: Microwave irradiation as a form of fixation for light and electron microscopy. J. Pathol. 146; 313-321, 1985.

9. Leong, A. S.-Y. and Milios, J.: Rapid immunoperoxidase staining of lymphocyte antigens using microwave irradiation. J. Pathol. 148; 183-187, 1986.

10. Login, R. G., Schnitt, S. J. and Dvorak, A. M.: Methods in laboratory investigation. Rapid microwave fixation of human tissues for light microscopic immunoperoxidase identification of diagnostically useful antigens. Lab. Invest. 7; 585-591, 1987.

11. Login, R. G., Galli, S. J., Morgan, E., Arizono, N., Schwarz, L. B. and Dvorak, A. M.: Rapid microwave fixation of rat mast cells. I. Localization of granule chymase with an ultrastructural postembedding immunogold technique. Lab. Invest. 57; 592-599, 1987.

12. Patterson, Jr. M. K. and Bulard, R.: Microwave fixation of cells in tissue culture. Stain Tech. 55; 71-75, 1980 . 
13. Singet, I. I., Scott, S., Kawka, D. W. and Hassell, J. R.: Extracellular matrix fibers containing fibronectin and basement membrane heparan sulfate proteoglycan coalign with focal contacts and microfilament bundles in stationary fibroblasts. Exp. Cell Res. 173; 558-571, 1987.

14. Yamamoto, N., Imazato, K. and Masumoto, A.: Growth stimulation of adult rat hepatocytes in a primary culture by soluble factor(s) secreted from nonparenchymal liver cell. Cell Struct. Funct. 14; 217-229, 1989.

15. Yasuda, K., Yamashita, S. and Shiozawa, M.: An experimental study on the application of microwave fixation to immunohistochemical studies. Acta histochem. cytochem. 22; 91-103, 1989. 